\title{
Identifying maternal deaths with the use of hospital data versus death certificates: a retrospective population-based study
}

\author{
Kayvan Aflaki BSc, Alison L. Park MSc, Chantal Nelson PhD, Wei Luo MBBS MSc, \\ Joel G. Ray MD MSc
}

\section{Abstract}

Background: Accurate identification of maternal deaths is paramount for audit and policy purposes. Our aim was to determine the accuracy and completeness of data on maternal deaths in hospital and those recorded on a death certificate, and the level of agreement between the 2 data sources.

Methods: We conducted a retrospective population-based study using data for Ontario, Canada, from Apr. 1, 2002, to Dec. 31, 2015. We used Canadian Institute for Health Information ( $\mathrm{ClHI}$ ) databases to identify deaths during inpatient, emergency department and same-day surgery encounters. We captured Vital Statistics deaths in the Office of the Registrar General, Deaths (ORGD) data set. Deaths were considered within 42 days and within 365 days after a pregnancy outcome (live birth, miscarriage, ectopic pregnancy or induced abortion) for all multiple and singleton pregnancies. We calculated agreement statistics and $95 \%$ confidence intervals (Cls).

Results: Among 1679455 live births and stillbirths, 398 pregnancy-related deaths in the ORGD data set were mapped to a birth in $\mathrm{CIHI}$ databases, and 77 (16.2\%) were not. Among 2039849 recognized pregnancies, 534 pregnancy-related deaths in the ORGD data set were linked to $\mathrm{CIHI}$ records, and 68 (11.3\%) were not. Among live births and stillbirths, after pregnancy-related deaths in the ORGD data set not matched to a maternal death in the $\mathrm{CIHI}$ databases were removed, concordance measures between $\mathrm{CIHI}$ and ORGD records for maternal death within 42 days after delivery included a $\kappa$ value of $0.87(95 \% \mathrm{Cl} 0.82-0.91)$ and positive percent agreement of $0.88(95 \% \mathrm{Cl} 0.83-0.94)$. The corresponding measures were similar for maternal death within 42 days after the end of a recognized pregnancy. When unlinked pregnancy-related deaths in the ORGD data set were retained, agreement measures declined for death within 42 days after a live birth or stillbirth $(\kappa=0.68,95 \% \mathrm{Cl} 0.62-0.74)$. For maternal death within 365 days after a live birth or stillbirth, or after the end of a recognized pregnancy, the concordance statistics were generally favourable when unlinked pregnancy-related deaths in the ORGD data set were removed but were substantially declined when they were retained.

Interpretation: Maternal mortality cannot be ascertained solely with the use of hospital data, including beyond 42 days after the end of pregnancy. To improve linkage, we propose including health insurance numbers on provincial and territorial medical death certificates.

\section{M} aternal death, although rare, is an often preventable event with devastating consequences for families and care providers. The World Health Organization estimates that more than 300000 women die each year from pregnancy- or childbirth-related complications. ${ }^{1}$ The World Health Organization and the Public Health Agency of Canada reported a rise in maternal mortality in Canada between 1990 and 2015, from 5.1 to 11.9 per 100000 live births., 2,3

These findings prompted the Society of Obstetricians and Gynaecologists of Canada to work with federal and provincial partners to review maternal mortality surveillance. ${ }^{4}$ The investigating committee found that national maternal health surveillance faced serious barriers relating to data access, coverage, timeliness and completeness. Moreover, they concluded that there was little standardization across jurisdictions with respect to definitions, data collection and maternal mortality review processes. ${ }^{4,5}$ Although several provinces and

\section{Competing interests: None declared.}

This article has been peer reviewed.

Correspondence to: Joel Ray, Joel.Ray@ unityhealth.to

CMAJ Open 2021. DOI:10.9778/cmajo.20200201 
territories have since established maternal death review committees, there is no national system to synthesize and report on maternal mortality and, thus, no accurate national picture of mortality prevalence and trends. ${ }^{3,4}$ This is especially so for maternal deaths occurring before the conventional birthing period, such as with an ectopic pregnancy, induced abortion or miscarriage, and those occurring up to 42 days after delivery.

Since Ontario contributes about $35 \%$ of all births in Canada, ${ }^{6,7}$ there arises an opportunity to examine the systems responsible for monitoring and recording maternal mortality. Accordingly, we conducted the current study to determine the accuracy and completeness of data on maternal deaths in hospital and those recorded on a death certificate, and the level of agreement between the 2 data sources by taking into consideration not only births, but also ectopic pregnancies, induced abortions and miscarriages, as well as capturing maternal deaths up to 365 days after the end of a pregnancy.

\section{Methods}

\section{Study design and data sources}

We performed this retrospective population-based study using data for the entire province of Ontario, Canada. We used existing data sets linked by means of unique encoded identifiers and analyzed at ICES. We used the Ontario Office of the Registrar General, Deaths (ORGD) data set to identify deaths based on a Medical Certificate of Death (Form 16), completed by a physician. ${ }^{8}$ The ORGD shares Vital Statistics death data with Statistics Canada for national reporting. The ORGD data set includes date and location of death and International Statistical Classification of Diseases and Related Health Problems, 10th Revision (ICD-10) codes for cause of death.

We identified deaths that occurred in a hospital setting using the Canadian Institute for Health Information (CIHI) Discharge Abstract Database (DAD), National Ambulatory Care Reporting System (NACRS) database and Same Day Surgery (SDS) database. ${ }^{9}$ The DAD contains administrative, clinical and demographic information pertaining to hospital discharges (i.e., deaths, sign-outs and transfers). Diagnostic codes are based on the Canadian version of the ICD-10 (ICD-10-CA), and procedural codes are based on the Canadian Classification of Health Interventions. ${ }^{10}$ The NACRS database contains information on hospital- and communitybased emergency and ambulatory care visits, and the SDS database contains patient-level data for day surgery institutions in Ontario. ${ }^{10,11}$

\section{Participants}

We identified live births and stillbirths in the DAD and the NACRS database. We used the DAD, the NACRS database and the SDS database to capture all recognized pregnancies, namely, a live birth, a stillbirth at 20 weeks' gestation or later, a miscarriage before 20 weeks' gestation, an ectopic pregnancy or an induced abortion for all multiple and singleton pregnancies. We used the ORGD data set to identify the deaths of females within 365 days after the end of a recognized pregnancy. We further used an ICD-10 cause of death code starting with "O" to identify a pregnancy-related death.

We included female Ontario residents aged 10-55 years at the time of a documented encounter for a recognized pregnancy outcome in the CIHI databases or with a registered death in the ORGD data set, for the period Apr. 1, 2002, to Dec. 31, 2015. We excluded records with an invalid Ontario Health Insurance Plan number or hospitalization number, a non-Ontario postal code at the time of delivery or death, or nonunique patient or hospital record identifiers. Continued residency in Ontario between the documented encounter date for a recognized pregnancy outcome and death was not a requirement for study inclusion. The CIHI and ORGD records were then linked by means of unique encrypted personal identifiers and date of death between 0 and 365 days after the pregnancy outcome date.

\section{Statistical analysis}

Among females who had a live birth or stillbirth in the CIHI databases and a death record in the ORGD data set, we described cause of death for those who died within 42 days after delivery, as well as from 43 to 365 days after delivery.

We generated agreement statistics (and 95\% confidence intervals [CIs]) from $2 \times 2$ tables describing the concordance between deaths identified in the CIHI databases and those in the ORGD data set, first for deaths among females with a live birth or stillbirth, and then among all recognized pregnancies, with consideration of deaths within 42 days and within 365 days of the end of the pregnancy. Agreement measures included Cohen $\kappa$, positive predictive value, negative predictive value, overall percent agreement, positive percent agreement and negative percent agreement. Overall percent agreement, positive percent agreement and negative percent agreement (calculations shown in Appendix 1, Table S1, available at www.cmajopen.ca/content/9/2/E539/suppl/DC1) are generally used in the absence of a perfect reference standard, ${ }^{12}$ as might be the case when using ORGD data, if a pregnancy is unrealized or maternal death is beyond 42 days after delivery. The agreement measures did include maternal deaths in the ORGD data set that were not linked to a recognized pregnancy in the CIHI databases.

\section{Ethics approval}

The use of data in this project was authorized under section 45 of Ontario's Personal Health Information Protection Act, which does not require review by a research ethics board.

\section{Results}

There were 2039849 recognized pregnancies in the study (Table 1), including 1679455 live birth or stillbirth deliveries identified in the DAD or NACRS database (Figure 1). We matched these 1679455 records to an identified maternal death in the ORGD data set (Figure 1). There were 398 pregnancy-related deaths in the ORGD data set that could be linked to a birth within the preceding 365 days in the DAD or NACRS database; 77 pregnancy-related deaths 
Table 1: Characteristics of recognized pregnancies in Ontario, Apr. 1, 2002, to Dec. 31, 2015, in the Canadian Institute for Health Information databases

\begin{tabular}{|lc|}
\hline Characteristic & $\begin{array}{c}\text { No. (\%) of } \\
\text { pregnancies* } \\
n=2039849\end{array}$ \\
\hline Mean age \pm SD, yr & $29.9 \pm 5.8$ \\
\hline Parity & $1(0-1)$ \\
\hline Median (IQR) & $826470(40.5)$ \\
\hline 0 & $629022(30.8)$ \\
\hline 1 & $244735(12.0)$ \\
\hline 2 & $115865(5.7)$ \\
\hline$\geq 3$ & $223757(11.0)$ \\
\hline Missing & $1668936(81.8)$ \\
\hline Outcome & $10069(0.5)$ \\
\hline \begin{tabular}{l} 
Live birth at $\geq 20$ weeks' gestation \\
\hline Stillbirth at $\geq 20$ weeks' gestation
\end{tabular} & $217474(10.7)$ \\
\hline Miscarriage or ectopic pregnancy & $143370(7.0)$ \\
\hline $\begin{array}{l}\text { Induced abortion } \\
\text { No. of weeks' gestation at birth, mean } \\
\pm \text { SD }\end{array}$ & $38.8 \pm 2.1$ \\
\hline $\begin{array}{l}\text { Note: IQR = interquartile range, SD = standard deviation. } \\
{ }^{*} \text { Except where indicated otherwise. } \\
\text { tRestricted to } 1679 \text { 005 obstetric deliveries resulting in a live birth or stillbirth. }\end{array}$ \\
\hline
\end{tabular}

(16.2\%) had no birth record in the CIHI databases (Figure 1). Cause of death within 42 days after the end of pregnancy, classified by the 3-digit ICD-10 code, is shown in Appendix 1, Table S2, and that for deaths between 43 and 365 days after the end of pregnancy is shown in Appendix 1, Table S3.

There were 2039849 recognized pregnancies in the DAD, NACRS database or SDS database, resulting in 1668936 live births (81.8\%), 10069 stillbirths (0.5\%), 217474 miscarriages or ectopic pregnancies (10.7\%), and 143370 induced abortions (7.0\%). A total of 534 pregnancyrelated deaths in the ORDG data set could be linked to the CIHI databases, and 68 (11.3\%) could not (Figure 2).

\section{Measures of concordance}

Among live births and stillbirths, after pregnancy-related deaths in the ORGD data set not matched to a maternal death in the CIHI databases were removed, concordance measures for maternal death within 42 days after delivery were high (Table 2). For example, the Cohen $\kappa$ was 0.87 (95\% CI 0.82 0.91), positive percent agreement 0.88 (95\% CI 0.83-0.94) and negative percent agreement 1.00 (95\% CI 1.00-1.00). For maternal deaths within 42 days after the end of a recognized pregnancy, the corresponding measures were 0.82 (95\% CI $0.78-0.87), 0.84$ (95\% CI $0.78-0.90)$ and 1.00 (95\% CI 1.00-1.00).

When unlinked pregnancy-related deaths in the ORGD data set were retained, however, agreement measures declined

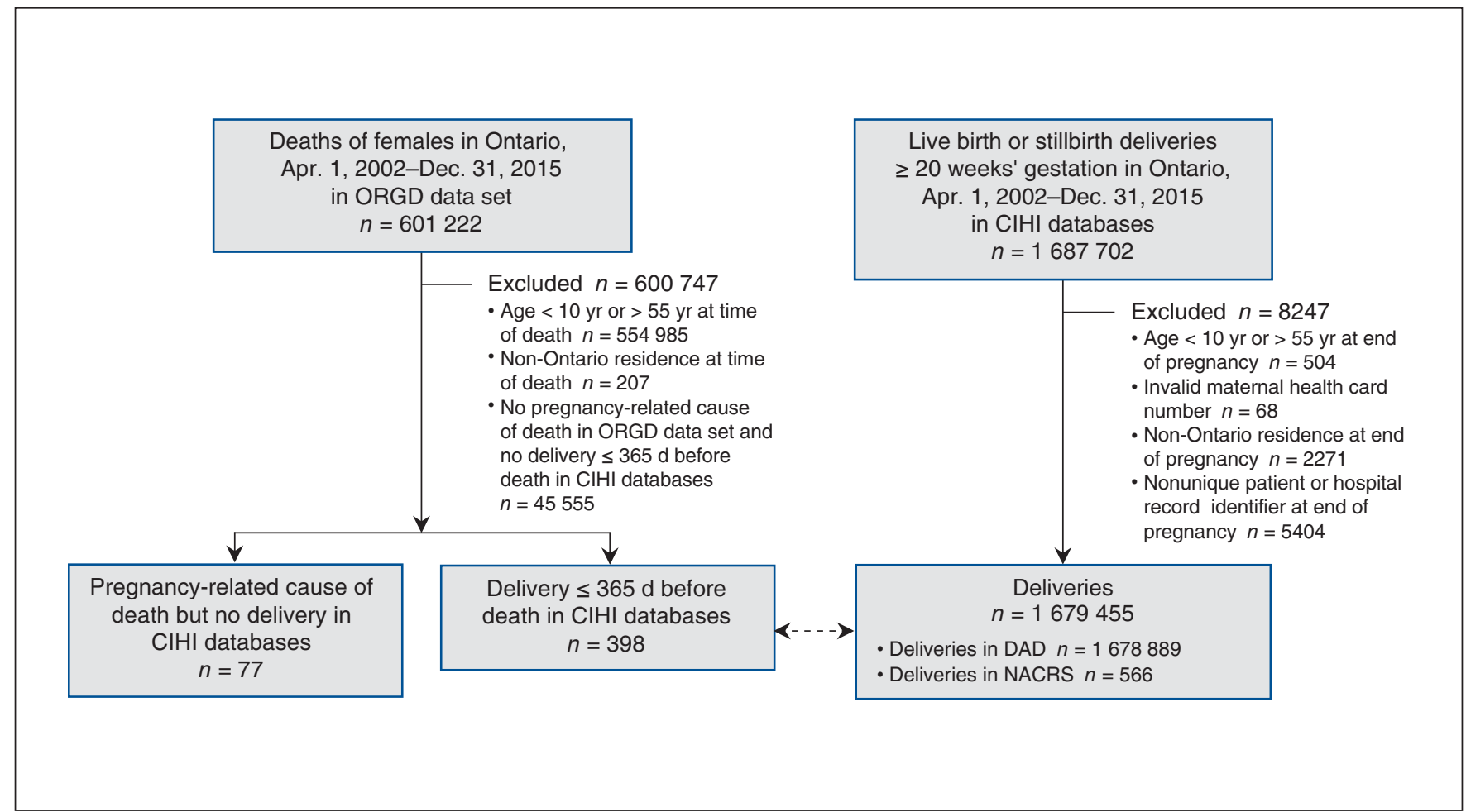

Figure 1: Flow diagram showing creation of a file (dashed line) linking the deaths of Ontario females of reproductive age between Apr. 1, 2002, and Dec. 31, 2015, in the Office of the Registrar General, Deaths (ORGD) data set with records of obstetric live births or stillbirths at 20 weeks' gestation or more in the Canadian Institute for Health Information (CIHI) Discharge Abstract Database (DAD) or National Ambulatory Care Reporting System (NACRS) database. 


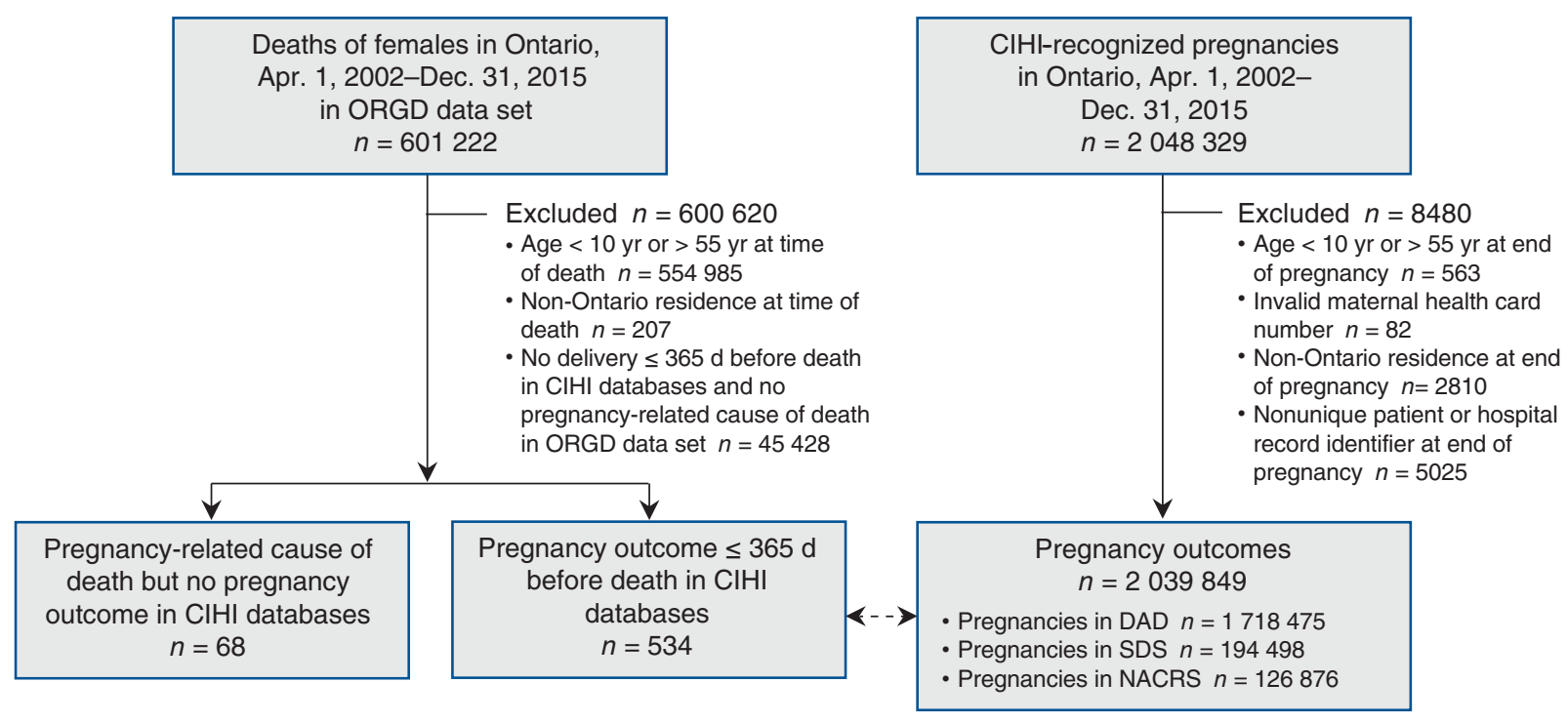

Figure 2: Flow diagram showing creation of a file (dashed line) linking the deaths of Ontario females of reproductive age between Apr. 1, 2002, and Dec. 31, 2015, in the Office of the Registrar General, Deaths (ORGD) data set with the records of females with any recognized pregnancy outcome in the Canadian Institute for Health Information (ClHI) Discharge Abstract Database (DAD), Same Day Surgery (SDS) database or National Ambulatory Care Reporting System (NACRS) database.

for maternal death within 42 days after a live birth or stillbirth (Cohen $\kappa=0.68$, 95\% CI 0.62-0.74; positive percent agreement $0.57,95 \%$ CI $0.50-0.63$ ) (Table 3). The same pattern was seen for maternal death within 42 days after the end of a recognized pregnancy (Table 3 ).

For maternal death within 365 days after a live birth or stillbirth, or within 365 days after the end of a recognized pregnancy, the concordance statistics were generally favourable when unlinked ORGD pregnancy-related deaths were removed (Table 4) but declined substantially when they were retained (Table 5).

\section{Interpretation}

In this population-based study, about $16 \%$ of maternal deaths following a live birth or stillbirth, and $11 \%$ of deaths after a recognized pregnancy (i.e., live birth, stillbirth, ectopic pregnancy, miscarriage or induced abortion) were not captured during a hospital encounter in CIHI databases when they were documented in the ORGD record. When linkage between the CIHI and ORGD records was possible, there was high concordance for maternal death, which declined when nonlinked cases were also considered.

A complete picture (the "universe") of maternal deaths in Canada is lacking. ${ }^{13}$ Nearly $60 \%$ of all deaths in Ontario between 2001 and 2015 occurred in a hospital setting. ${ }^{14}$ Our findings suggest that maternal mortality cannot be ascertained solely with the use of hospital data and highlight the need for improved methodology to effectively capture maternal mortality beyond 42 days after the end of pregnancy.

It would be challenging to develop a national enquiry system for maternal mortality, given Canada's provincebased approach to health care administration. Nevertheless, Canadian provinces and territories can, and do, collaborate in the design, development and collection of national disease surveillance. ${ }^{4}$ Replication of the current study methods in other provinces and the territories would be one step in achieving a better perspective about how maternal deaths can be captured accurately and efficiently; this should include input from the chief coroner of each province and territory.

To ascertain more accurate and complete information on maternal mortality, and to enable deterministic linkage between hospital and Vital Statistics data sources, we suggest amending provincial and territorial death certificates to include a fillable field for a provincial or territorial health insurance plan number, such as the Ontario Health Insurance Plan number in Ontario. We also suggest that all pregnancies be captured - regardless of how the pregnancy ends - with the inclusion of women who die while still pregnant.

\section{Limitations}

Not all miscarriages or induced abortions are captured by the data sets used in this study. ${ }^{15,16}$ To parallel the data sets currently available to the Canadian Perinatal Surveillance 


\begin{tabular}{|c|c|c|c|}
\hline \multirow[b]{2}{*}{$\mathrm{ClHI}$} & \multicolumn{2}{|c|}{ ORGD } & \multirow[b]{2}{*}{ Total } \\
\hline & Yes & No & \\
\hline \multicolumn{4}{|c|}{ Maternal death within $\mathbf{4 2} \mathrm{d}$ of live birth or stillbirth, DAD or NACRS v. ORGD } \\
\hline Yes & 122 & 22 & 144 \\
\hline No & 16 & 1679295 & 1679311 \\
\hline Total & 138 & 1679317 & 1679455 \\
\hline Agreement indicator & Value $(95 \% \mathrm{Cl})$ & & \\
\hline Cohen $\kappa$ & $0.87(0.82-0.91)$ & & \\
\hline Positive predictive value & $0.85(0.79-0.91)$ & & \\
\hline Negative predictive value & $1.00(1.00-1.00)$ & & \\
\hline Overall percent agreement & $1.00(1.00-1.00)$ & & \\
\hline Positive percent agreement & $0.88(0.83-0.94)$ & & \\
\hline Negative percent agreement & $1.00(1.00-1.00)$ & & \\
\hline \multicolumn{4}{|c|}{ Maternal death within $42 \mathrm{~d}$ of end of recognized pregnancy, DAD, NACRS or SDS v. ORGD } \\
\hline Yes & 137 & 34 & 171 \\
\hline No & 26 & 2039641 & 2039667 \\
\hline Total & 163 & 2039675 & 2039838 \\
\hline Agreement indicator & Value $(95 \% \mathrm{Cl})$ & & \\
\hline Cohen $\kappa$ & $0.82(0.78-0.87)$ & & \\
\hline Positive predictive value & $0.80(0.74-0.86)$ & & \\
\hline Negative predictive value & $1.00(1.00-1.00)$ & & \\
\hline Overall percent agreement & $1.00(1.00-1.00)$ & & \\
\hline Positive percent agreement & $0.84(0.78-0.90)$ & & \\
\hline Negative percent agreement & $1.00(1.00-1.00)$ & & \\
\hline
\end{tabular}

System, we opted to use only the CIHI and Vital Statistics files. A broader data set might also include data such as provincial billing information, which would enhance the capture of induced abortion codes. ${ }^{15,16}$ For example, in a study from British Columbia, Canada, the sensitivity of identifying induced abortion in the DAD was $91.9 \%$; this increased to $99.1 \%$ when physician billing codes were also used. ${ }^{16}$ Furthermore, out-of-hospital births are not documented completely in the current administrative databases. ${ }^{17}$ Pregnancy-related deaths in the ORGD data set not captured by CIHI may be attributable to deaths during home delivery or out-of-hospital maternal deaths.

A second major limitation is that there were inherent problems in creating the current data linkages. In Ontario, a Medical Certificate of Death does not include a fillable field for an Ontario Health Insurance Plan number, which serves as a unique identifier for all residents of Ontario. Matching maternal deaths in the Vital Statistics registry to hospitalization information depended on a probabilistic linkage method, which uses nonunique linkage keys, such as first and last name combinations and date of birth. Such an approach is prone to false-positive and false-negative linkages. ${ }^{18}$ For example, if we were unable to link a hospital record to an existing Vital Statistics record with certainty, the hospital record was deemed a nonmatch.

The age of our data represents a limitation to our study, as the comprehensiveness of CIHI data holdings may have improved since $2015 .{ }^{19}$ In addition, ICD-10-CA diagnostic codes include up to 6 characters in hospital data, whereas only the first 4 characters are used in Vital Statistics data, based on ICD-10 codes. Furthermore, Canadian provinces 


\begin{tabular}{|c|c|c|c|}
\hline \multirow[b]{2}{*}{$\mathrm{ClHI}$} & \multicolumn{2}{|c|}{ ORGD } & \multirow[b]{2}{*}{ Total } \\
\hline & Yes & No & \\
\hline \multicolumn{4}{|c|}{ Maternal death within $42 \mathrm{~d}$ of live birth or stillbirth, DAD or NACRS v. ORGD } \\
\hline Yes & 122 & 22 & 144 \\
\hline No & 93 & 1679295 & 1679388 \\
\hline Total & 215 & 1679317 & 1679532 \\
\hline Agreement indicator & Value $(95 \% \mathrm{Cl})$ & & \\
\hline Cohen $\kappa$ & $0.68(0.62-0.74)$ & & \\
\hline Positive predictive value & $0.85(0.79-0.91)$ & & \\
\hline Negative predictive value & $1.00(1.00-1.00)$ & & \\
\hline Overall percent agreement & $1.00(1.00-1.00)$ & & \\
\hline Positive percent agreement & $0.57(0.50-0.63)$ & & \\
\hline Negative percent agreement & $1.00(1.00-1.00)$ & & \\
\hline \multicolumn{4}{|c|}{$\begin{array}{l}\text { Maternal death within } 42 \mathrm{~d} \text { of end of a recognized pregnancy, DAD, NACRS or CIHI-SDS v. } \\
\text { ORGD }\end{array}$} \\
\hline Yes & 137 & 34 & 171 \\
\hline No & 94 & 2039652 & 2039746 \\
\hline Total & 231 & 2039686 & 2039917 \\
\hline Agreement indicator & Value $(95 \% \mathrm{Cl})$ & & \\
\hline Cohen $\kappa$ & $0.68(0.63-0.73)$ & & \\
\hline Positive predictive value & $0.80(0.74-0.86)$ & & \\
\hline Negative predictive value & $1.00(1.00-1.00)$ & & \\
\hline Overall percent agreement & $1.00(1.00-1.00)$ & & \\
\hline Positive percent agreement & $0.59(0.53-0.66)$ & & \\
\hline Negative percent agreement & $1.00(1.00-1.00)$ & & \\
\hline
\end{tabular}

differentially switched from the Canadian version of the International Classification of Diseases, 9th Revision to ICD10-CA over an 8-year period, starting around 2000. This staggered introduction of ICD-10-CA coding may have affected the quality of data available in provincial hospital administrative data, limiting the generalizability of our findings to some parts of Canada.

Births occurring outside of a traditional health care setting, such as a birthing centre or private residence, are not captured in the DAD or the NACRS or SDS databases, and would not be included in the current study. In addition, maternal deaths occurring outside of a health care setting may not have been documented in the ORGD data set. Last, deaths within the CIHI databases are not linkable for people without a registered provincial health insurance plan number, which might miss maternal deaths among temporary visa holders, recent refugees and undocumented residents, the majority of whom reside in larger urban centres, including Toronto. ${ }^{20-22}$ Hence, the true scope of maternal mortality in Ontario may be higher than that estimated in the current study.

\section{Conclusion}

Vital Statistics death records likely capture the scope of maternal deaths in Ontario more accurately and more completely than the use of CIHI hospital records alone. To improve the quality of data linkage, we propose amending provincial and territorial medical death certificates to include fields for health insurance numbers, and the capture of all deaths during or after pregnancy. 


\begin{tabular}{|c|c|c|c|}
\hline \multicolumn{4}{|c|}{ Maternal death within $365 \mathrm{~d}$ of live birth or stillbirth, DAD or NACRS v. ORGD } \\
\hline Yes & 278 & 34 & 312 \\
\hline No & 120 & 1679023 & 1679143 \\
\hline Total & 398 & 1679057 & 1679455 \\
\hline Agreement indicator & Value $(95 \% \mathrm{Cl})$ & & \\
\hline Cohen $\kappa$ & $0.78(0.75-0.82)$ & & \\
\hline Positive predictive value & $0.89(0.86-0.93)$ & & \\
\hline Negative predictive value & $1.00(1.00-1.00)$ & & \\
\hline Overall percent agreement & $1.00(1.00-1.00)$ & & \\
\hline Positive percent agreement & $0.70(0.65-0.74)$ & & \\
\hline Negative percent agreement & $1.00(1.00-1.00)$ & & \\
\hline \multicolumn{4}{|c|}{ Maternal death within $365 \mathrm{~d}$ of end of a recognized pregnancy, DAD, NACRS or SDS v. ORGD } \\
\hline Yes & 346 & 47 & 393 \\
\hline No & 188 & 2039257 & 2039445 \\
\hline Total & 534 & 2039304 & 2039838 \\
\hline Agreement indicator & Value $(95 \% \mathrm{Cl})$ & & \\
\hline Cohen $\kappa$ & $0.75(0.72-0.78)$ & & \\
\hline Positive predictive value & $0.88(0.85-0.91)$ & & \\
\hline Negative predictive value & $1.00(1.00-1.00)$ & & \\
\hline Overall percent agreement & $1.00(1.00-1.00)$ & & \\
\hline Positive percent agreement & $0.65(0.61-0.69)$ & & \\
\hline Negative percent agreement & $1.00(1.00-1.00)$ & & \\
\hline
\end{tabular}

\section{References}

1. Alkema L, Chou D, Hogan D, et al.; United Nations Maternal Mortality Estimation Inter-Agency Group collaborators and technical advisory group. Global, regional, and national levels and trends in maternal mortality between 1990 and 2015, with scenario-based projections to 2030: a systematic analysis by the UN Maternal Mortality Estimation Inter-Agency Group. Lancet 2016;387:462-74.

2. Say L, Chou D, Gemmill A, et al. Global causes of maternal death: a WHO systematic analysis. Lancet Glob Health 2014;2:e323-33.

3. Perinatal health indicators for 2017. Ottawa: Public Health Agency of Canada; 2017.

4. Cook JL, Sprague AE; members of the Society of Obstetricians and Gynaecologists of Canada's Maternal Mortality Pilot Project. Measuring maternal mortality in Canada: an update on the establishment of a confidential enquiry system for preventing maternal deaths \#savingmoms \#savingbabies. 7 Obstet Gynaecol Can 2019;41:1768-71.

5. Allen VM, Campbell M, Carson G, et al. Maternal mortality and severe maternal morbidity surveillance in Canada. $\mathcal{F}$ Obstet Gynaecol Can 2010;32:1140-6.

6. Table 17-10-0008-01: Estimates of the components of demographic growth, annual. Ottawa: Statistics Canada. Available: www150.statcan.gc.ca/t1/tbl1/en/tv. action?pid=1710000801 (accessed 2020 July 5).

7. Ontario population projections, 2018-2046. Toronto: Ontario Ministry of Finance; 2019.
8. Vital Statistics mortality data. Association of Public Health Epidemiologists in Ontario. Available: www.apheo.ca/data-vital-stats-mortality (accessed 2020 July 5).

9. Hospital standardized mortality ratio (HSMR). Ottawa: Canadian Institute for Health Information. Available: www.cihi.ca/en/hospital-standardized -mortality-ratio-hsmr (accessed 2020 July 5).

10. Discharge Abstract Database metadata (DAD). Ottawa: Canadian Institute for Health Information. Available: www.cihi.ca/en/discharge-abstract-database -metadata-dad (accessed 2020 July 5).

11. National Ambulatory Care Reporting System metadata (NACRS). Ottawa: Canadian Institute for Health Information. Available: www.cihi.ca/en/national -ambulatory-care-reporting-system-metadata-nacrs (accessed 2020 July 5).

12. Guidance for industry and FDA staff: statistical guidance on reporting results from studies evaluating diagnostic tests. Rockville (MD): Center for Devices and Radiological Health, U.S. Food and Drug Administration; 2007. Available: https://www.fda.gov/downloads/medicaldevices/deviceregulationandguidance/ guidancedocuments/ucm071287.pdf (accessed 2021 May 7).

13. Trends in maternal mortality: 2000 to 2017. Estimates by WHO, UNICEF, UNFPA, World Bank Group and the United Nations Population Division: executive summary. Geneva: World Health Organization; 2019. Available: www.unfpa.org/sites/ default/files/resource-pdf/Maternal_mortality_exec_summary.pdf (accessed 2020 Feb. 29). 
Table 5: Agreement between Canadian Institute for Health Information (CIHI) and Office of the Registrar General, Deaths (ORGD) records for maternal death within 365 days of a pregnancy outcome, including ORGD pregnancy-related deaths not matched to a maternal death within $\mathrm{CIHI}$ databases in the numerator and denominator during percent agreement calculations

\begin{tabular}{|c|c|c|c|}
\hline \multirow[b]{2}{*}{$\mathrm{ClHI}$} & \multicolumn{2}{|c|}{ ORGD } & \multirow[b]{2}{*}{ Total } \\
\hline & Yes & No & \\
\hline \multicolumn{4}{|c|}{ Maternal death within $365 \mathrm{~d}$ of live birth or stillbirth, DAD or NACRS v. ORGD } \\
\hline Yes & 278 & 34 & 312 \\
\hline No & 197 & 1679023 & 1679220 \\
\hline Total & 475 & 1679057 & 1679532 \\
\hline Agreement indicator & Value $(95 \% \mathrm{Cl})$ & & \\
\hline Cohen $\kappa$ & $0.71(0.82-0.91)$ & & \\
\hline Positive predictive value & $0.89(0.86-0.93)$ & & \\
\hline Negative predictive value & $1.00(1.00-1.00)$ & & \\
\hline Overall percent agreement & $1.00(1.00-1.00)$ & & \\
\hline Positive percent agreement & $0.59(0.54-0.63)$ & & \\
\hline Negative percent agreement & $1.00(1.00-1.00)$ & & \\
\hline \multicolumn{4}{|c|}{ Maternal death within $365 \mathrm{~d}$ of end of a recognized pregnancy, DAD, NACRS or SDS v. ORGD } \\
\hline Yes & 346 & 47 & 393 \\
\hline No & 256 & 2039268 & 2039524 \\
\hline Total & 602 & 2039315 & 2039917 \\
\hline Agreement indicator & Value $(95 \% \mathrm{Cl})$ & & \\
\hline Cohen $\kappa$ & $0.70(0.66-0.73)$ & & \\
\hline Positive predictive value & $0.88(0.85-0.91)$ & & \\
\hline Negative predictive value & $1.00(1.00-1.00)$ & & \\
\hline Overall percent agreement & $1.00(1.00-1.00)$ & & \\
\hline Positive percent agreement & $0.57(0.54-0.61)$ & & \\
\hline Negative percent agreement & $1.00(1.00-1.00)$ & & \\
\hline
\end{tabular}

14. Table 13-10-0715-01: Deaths, by place of death (hospital or non-hospital). Ottawa: Statistics Canada. Available: www150.statcan.gc.ca/t1/tbl1/en/tv.action?pid= 1310071501 (accessed 2020 July 5).

15. Liu N, Farrugia MM, Vigod SN, et al. Intergenerational abortion tendency between mothers and teenage daughters: a population-based cohort study. CMA7 2018;190:E95-102.

16. Samiedaluie S, Peterson S, Brant R, et al. Validating abortion procedure coding in Canadian administrative databases. BMC Health Serv Res 2016;16:255.

17. Ray JG, Park AL, Dzakpasu S, et al. Prevalence of severe maternal morbidity and factors associated with maternal mortality in Ontario, Canada. $7 A M A N e t w$ Open 2018;1:e184571.

18. Moore CL, Gidding HF, Law MG, et al. Poor record linkage sensitivity biased outcomes in a linked cohort analysis. 7 Clin Epidemiol 2016;75:70-7.

19. CIHI's annual report, 2018-2019: 25 years of CIHI. Ottawa: Canadian Institute for Health Information; 2019. Available: https://secure.cihi.ca/free_products/ cihi-annual-report-2018-2019-en.pdf (accessed 2020 July 5).

20. Magalhaes L, Carrasco C, Gastaldo D. Undocumented migrants in Canada: a scope literature review on health, access to services, and working conditions. $\mathcal{F}$ Immigr Minor Health 2010;12:132-51.

21. Bernhard JK, Goldring L, Young J, et al. Living with precarious legal status in Canada: implications for the well-being of children and families. Refuge 2007; 24:101-14.
22. Campbell RM, Klei AG, Hodges BD, et al. A comparison of heath access between permanent residents, undocumented immigrants and refugee claimants in Toronto, Canada. F Immigr Minor Health 2014;16:165-76.

Affiliations: Institute of Medical Science (Aflaki), University of Toronto; ICES Central (Park), Toronto, Ont.; Maternal, Child and Youth Health Division (Nelson, Luo), Centre for Surveillance and Applied Research, Public Health Agency of Canada, Ottawa, Ont.; Departments of Medicine (Ray) and Obstetrics and Gynecology (Ray), St. Michael's Hospital, Toronto, Ont.

Contributors: Chantal Nelson, Alison Park and Joel Ray conceived of the study. Chantal Nelson, Wei Luo, Alison Park and Joel Ray designed the study. Kayvan Aflaki, Alison Park and Joel Ray drafted the manuscript. All of the authors contributed to data analysis and interpretation, revised the manuscript critically for important intellectual content, approved the final version to be published and agreed to be accountable for all aspects of the work.

Funding: This study was funded by the Public Health Agency of Canada and was supported by ICES, which is funded by an annual grant from the Ontario Ministry of Health. 
Content licence: This is an Open Access article distributed in accordance with the terms of the Creative Commons Attribution (CC BY-NCND 4.0) licence, which permits use, distribution and reproduction in any medium, provided that the original publication is properly cited, the use is noncommercial (i.e., research or educational use), and no modifications or adaptations are made. See: https://creativecommons.org/licenses/ by-nc-nd/4.0/.

Data sharing: The data set from this study is held securely in coded form at ICES. Although data-sharing agreements prohibit ICES from making the data set publicly available, access may be granted to those who meet prespecified criteria for confidential access, available at https:// www.ices.on.ca/DAS. The full data set creation plan and underlying analytic code are available from the authors on request, with the understanding that the computer programs may rely on coding templates or macros that are unique to ICES and are therefore inaccessible or may require modification.

Disclaimer: Parts of this material are based on data and information compiled and provided by the Ontario Ministry of Health and the Canadian Institute for Health Information. The analyses, conclusions, opinions and statements expressed herein are solely those of the authors and do not reflect those of the funding or data sources; no endorsement is intended or should be inferred. Parts of this report are based on Ontario Registrar General (ORG) information on deaths, the original source of which is ServiceOntario. The views expressed herein are those of the authors and do not necessarily reflect those of the ORG or the Ministry of Government Services.

Supplemental information: For reviewer comments and the original submission of this manuscript, please see www.cmajopen.ca/content/9/2/ E539/suppl/DC1. 